\title{
Uterine Necrosis After Uterine Artery Embolization (UAE) - Rare Entity with a Dilemma
}

Shama Chaudry', Navaira Azeem², Eugen Khang ${ }^{2}$

'Department of Obstetrics and Gynecology, Ziauddin University Hospital, ${ }^{2} S t u d e n t$, Ziauddin University, Karachi, Pakistan.

\begin{abstract}
Uterine artery embolization (UAE), a minimally invasive procedure used for controlling and managing profuse bleeding in conditions like uterine fibroids, and uterine hemorrhage, in cases of intractable postpartum hemorrhage (PPH). A wide array of complications due to UAE includes pulmonary embolism, uterine ischemia, necrosis, sepsis, and death. A 27 years old married woman (parity 1+2) presented with complaints of a mass protruding of the vagina with dirty brown vaginal discharge. Following UAE was done for postpartum hemorrhage (PPH) she had developed fever and burning micturition on which ultrasound was done to show an anteverted, enlarged, bulky uterus, with multiple endogenic foci, with endometrial canal and adjacent myometrium suggestive of infective pathology. In this case report complications of UAE for the management of PPH were discussed, however, research is required to comprehend the causes of uterine necrosis following uterine artery embolization and its management.
\end{abstract}

Keywords: Uterine Artery Embolization; Postpartum Hemorrhage; Uterine Necrosis; Pathology.

\author{
Corresponding Author: \\ Navaira Azeem \\ Ziauddin University, \\ Karachi, Pakistan. \\ Email: navairaazeem106@gmail.com \\ https://doi.org/10.36283/PJMD11-1/014
}

How to cite: Chaudry S, Azeem N, Khang E. Uterine Necrosis After Uterine Artery Embolization (UAE) - Rare Entity with a Dilemma. 2022;1 1(1): 85-88. doi: 10.36283/PJMD1 1-1/014

\section{INTRODUCTION}

Uterine artery embolization (UAE) is a procedure done for intractable postpartum hemorrhage (PPH), which while preserving fertility can save lives, ${ }^{1,2}$. Complications of UAE include postembolization syndrome, post-procedure pain, infection, persistent per vagina (PV) discharge, fibroid passage PV, endometrial atrophy which can then lead to secondary amenorrhea, nontarget embolization, and uterine necrosis ${ }^{3}$. However, only about 19 cases have been documented for UAE resulting in uterine necrosis, remaining one of the rarest complications ${ }^{4}$. A total of seven cases of uterine hysterectomy performed due to uterine infarction have been described; two of these cases occurred following UAE for PPH, while five cases occurred following UAE for uterine fibroids ${ }^{5}$. Here, we report a case of uterine necrosis with chronic uterine inversion following UAE for PPH.

\section{CASE PRESENTATION}

A 27-year-old woman, parity $2+1$, married for 5 years was referred from a hospital with complaints of something coming out of the vagina for a few hours and dirty brown vaginal discharge. The discharge was not associated with any itch or smell. She had a history of Spontaneous Vaginal Delivery (SVD) with episiotomy 2 months back.

At the time the patient was 26 weeks pregnant and presented with excessive vomiting and shortness of breath. Her U/S abdomen of the liver showed fatty changes while her CXR appreciated a pulmonary 
infection. COVID-19 PCR was negative. The investigations showed low platelets ( $40 \times 10 \wedge 9)$, increased TLC (17.9 x 10^9) and deranged LFTs (PT: 15.6, INR: 1.42, Direct bilirubin: 0.80, Total bilirubin: 1.15, ALT: 1 146, AST: 4367). She was then diagnosed with Acute Fatty Liver of Pregnancy (AFLP). After conservative management, the patient developed Grade 2-3 Hepatic Encephalopathy. This led to her developing hepatic liver failure and becoming extremely ill and drowsy. She was induced for labor on 15th April 2021. The fetus was expelled via spontaneous vaginal delivery. It was an alive male of $600 \mathrm{gm}$ shifted to NICU. The same night she went into severe PPH again and hence, uterine artery embolization (UAE) was done. This was done by injecting 355 hundred millimicrons of Polyvinyl alcohol (PVA particles) in gel form into the uterine artery through a small catheter thus cutting off the blood supply. Her condition improved drastically after the termination of the pregnancy and she was discharged in a stable condition.
She was admitted again on 27th April 2021 with complaints of fever for 8 days and burning micturition. The diagnosis confirmed urinary tract infection (UTI) as $\mathrm{CBC}$ showed $\mathrm{Hb}=7.5, \mathrm{TLC}=15.5$, Platelets $=448$. Her Urine D/R showed blood positive (+3) and numerous bacteria. Three days later, her labs showed $\mathrm{Hb}=6.2$, $\mathrm{TLC}=12.7$ and Platelet= 262. Urine culture isolated Yeast Candida Albicans. A U/S pelvis appreciated an anteverted, enlarged bulky uterus- multiple endogenic foci with dirty shadowing representing air noted with endometrial canal and adjacent myometrium suggestive of endometritis (Table 1). She was managed conservatively and transfused blood. She reacted to $2 \mathrm{PCV}$ transfused blood on both occasions which included; vomiting, shivering, excessive urination, and cough. The blood was stopped immediately. She was given a range of antibiotics and sent home.

Table 1: Predicting and monitoring the clinical parameters.

\begin{tabular}{|l|c|c|c|c|c|}
\hline Parameters & $\mathbf{1 3}^{\text {th }}$ April & $\mathbf{1 6}^{\text {th }}$ April & $\mathbf{1}^{\text {st }}$ May & $\mathbf{1 5}^{\text {th }} \mathbf{~ J n e ~}$ & Predictive Values \\
\hline $\mathrm{Hb}$ & 9.2 & 9.7 & 8.0 & 11.7 & $11.5-15.4 \mathrm{mg} / \mathrm{dl}$ \\
\hline $\mathrm{TLC}$ & 17.9 & 24 & 21.2 & 10 & $4-10 \times 10 \wedge 9$ \\
\hline Platelet & 40 & 105 & 220 & 349 & $150-440 \times 10 \wedge 9 \mathrm{~L}$ \\
\hline $\mathrm{PT}$ & 15.6 & 13.2 & 11.5 & 11.1 & $9-13 \mathrm{sec}$ \\
\hline $\mathrm{INR}$ & 1.42 & 1.19 & 1.04 & 1.09 & $2-4.5 \mathrm{sec}$ \\
\hline ALT & 1146 & 233 & 24 & 64 & $<34 \mathrm{U} / \mathrm{L}$ \\
\hline AST & 4367 & 262 & 82 & 101 & $<31 \mathrm{U} / \mathrm{L}$ \\
\hline B. Total & 1.15 & 5.64 & 0.58 & 0.25 & $0.3-1.2 \mathrm{mg} / \mathrm{dl}$ \\
\hline B. Direct & 0.80 & 3.12 & 0.26 & 0.12 & $<0.2 \mathrm{mg} / \mathrm{dl}$ \\
\hline ALP & 251 & 225 & 129 & 162 & $42-98 \mathrm{U} / \mathrm{L}$ \\
\hline
\end{tabular}

After 5 weeks, she complained of something coming out of her vagina in the washroom during micturition. For that, she went to another hospital and got her problem relieved by manual replacement by hand in the labor room and was then referred to Ziauddin Hospital North for further management.

Thus, her current admission showed BP at 140/95 $\mathrm{mmHg}$ and pulse at $92 \mathrm{bpm}$. On examination, her abdomen was soft and non-tender and she had normal vesicular breathing. On local examination, a pinkish white globular mass without purulent flakes was observed protruding from the introitus, suggestive of necrosis of uterus/chronic uterine inversion. Her total abdominal hysterectomy with bilateral salpingectomy was done (Figure la, b). Histopathology was conducted that concluded while areas of coagulative necrosis were present, there were no signs of mitotic activity and nuclear pleomorphism (Figure 2a, b). The report associated necrosis in the leiomyomas with pregnancy and appreciated embolizing material in the blood vessels.

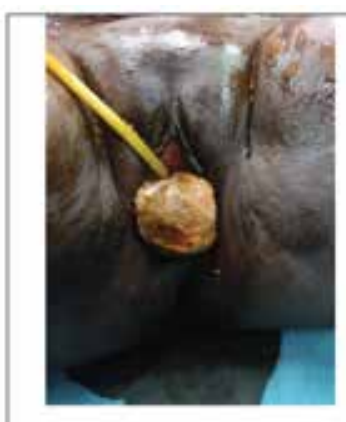

(a)

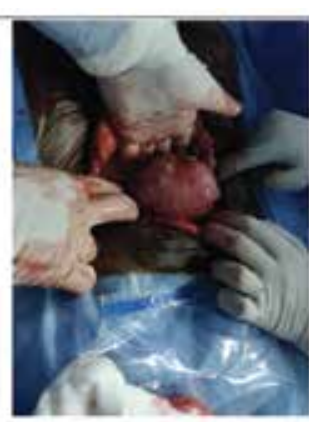

(b)

Figure 1: (a) Necrosed uterus after uterine artery embolization; (b) removal of the necrosed uterus through total abdominal hysterectomy. 


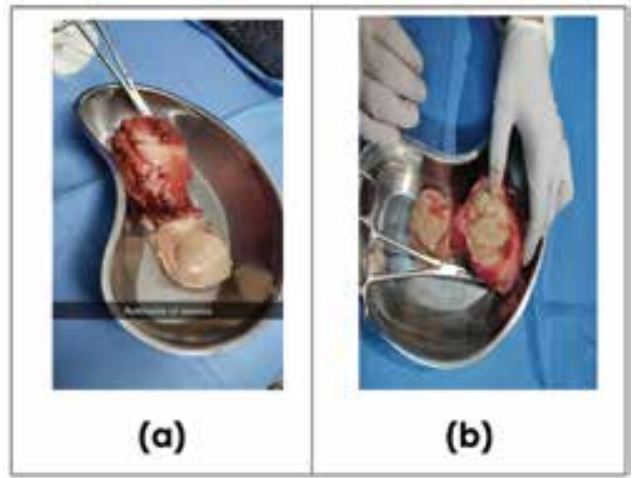

Figure 2: (a) Autolysis of serosa; (b) necrosed uterus after extraction from a total abdominal hysterectomy.

\section{DISCUSSION}

Uterine artery embolization is a minimally invasive technique that has been used widely to save lives. However, like any other procedure, it comes with the risk of a few complications. UAE can lead to complications including postembolization syndrome, post-procedure pain, infection, endometrial atrophy leading to secondary amenorrhea, and uterine necrosis ${ }^{6.7}$. One of these complications includes uterine infarction especially in those patients where the anastomoses of ovarian to the uterine artery are significant ${ }^{8}$. A study was conducted in Wisconsin in which UAE was indicated to a 29 -year-old nulliparous woman who gave birth to two twin males via LSCS and had complications of severe $\mathrm{PPH}^{9}$. The patient at the time was bleeding profusely and had severe anemia. For the entirety of the procedure, the embolizing agent used was gelfoam slurry and 500-to-700-micron embosphere ${ }^{10}$.

There were no post-op complications after which the patient was discharged, only to return 4 weeks later with complaints of low-grade fever and a tender uterus. Upon the indication of TAH, a soft, friable, necrotic, and foul-smelling uterus was obtained. Pathologic examination revealed an infracted myometrium with areas of necrosis ${ }^{11,12}$. Another study conducted in the States reported a $56 y e a r s$ old African woman who complained of persistent vomiting, smelly brown discharge, and severe lower abdominal pain that lasted a month after $U A E^{13}$. Spongostan Gelfoam slurry was used to perform the UAE and her $C B C$ showed a low HB count. Again, TAH was indicated after which a necrosed uterus was revealed with thin serosal mucosa that was adhered to the large and small bowel. Although the exact cause of UAE is difficult to determine, there are a few theories that try to explain its incidence ${ }^{14}$. Since the accessory supply to the uterus provided by the utero-ovarian and cervicovaginal vessels is also embolized using fine particles (<500 micrometers) the first theory hypothesizes that post-UAE necrosis may be a complication of this procedure ${ }^{15}$. The other theory postulates that the use of a specific spherical poly-vinyl alco- hol agent (PVA) as an embolizing agent may also predispose to uterine necrosis. Lastly, other theories that exist include the lack of antibiotic prophylaxis after UAE and the existence of sepsis ${ }^{15}$. The patient had PVA particles used during her UAE that were less than 500 micrometers thus proving some theories but disregarding others as she was given prophylactic antibiotics and had a case of sepsis.

The treatment of choice not only depends on the associated complications but also on the severity of the patient's symptoms. Conservative management has also been described in the literature as an option for a handful of patients, however, multiple studies have proved that TAH is the treatment of choice. The patient after failing to respond to conservative management, including antibiotics and oral analgesics, was indicated TAH+BS. The prognosis was good after surgery and the patient seemed to recover well.

\section{CONCLUSION}

Uterine artery embolization could lead to uterine necrosis in the management of postpartum hemorrhage. The only treatment for most of such cases was found to be Abdominal Hysterectomy. More research needs to be conducted on the causes of uterine necrosis following uterine artery embolization as it is a rare finding.

\section{ACKNOWLEDGEMENTS}

The authors are specifically thankful to the Radiology Department of Ziauddin Hospital North Nazimabad campus for providing them with reports and their cooperation in briefing it.

\section{CONFLICT OF INTEREST}

The authors declared no conflict of interest.

\section{PATIENT CONSENT}

Patient consent was taken before starting the procedure and for publishing.

\section{AUTHORS' CONTRIBUTION}

SC gave the idea and supervised the study; NA 
collected the data; NA and EK wrote the manuscript; EK conducted the literature search.

\section{REFERENCES}

1. Doumouchtsis SK, Nikolopoulos K, Talaulikar VS, Krishna A, Arulkumaran S. Menstrual and fertility outcomes following the surgical management of postpartum hemorrhage: a systematic review. BJOG: Int J Obstet Gynaecol. 2014;121(4):382-388. doi: 10.1111/1471-0528.12546

2. Chauleur C, Fanget C, Tourne G, Levy R, Larchez C, Seffert P. Serious primary post-partum hemorrhage, arterial embolization and future fertility: a retrospective study of 46 cases. Hum Reprod. 2008;23(7):1553-1559. doi: 10.1093/humrep/den122

3. Gupta JK, Sinha A, Lumsden MA, Hickey M. Uterine artery embolization for symptomatic uterine fibroids. Cochrane Database Syst Rev. 2014;(12):1-51. doi: 10.1002/14651858.CD005073.pub4

4. Poujade O, Ceccaldi PF, Davitian C, Amate P, Chatel $\mathrm{P}$, Khater $\mathrm{C}$, et al. Uterine necrosis following pelvic arterial embolization for post-partum hemorrhage: review of the literature. Eur J Obstet Gynecol Reprod Biol. 2013;170(2):309-314. doi: 10.1016/j.ejog rb.2013.07.016

5. Cottier JP, Fignon A, Tranquart F, Herbreteau D. Uterine necrosis after arterial embolization for postpartum hemorrhage. Obstet Gynecol. 2002;100 (5):1074-1077.

6. Pirard C, Squifflet J, Gilles A, Donnez J. Uterine necrosis and sepsis after vascular embolization and surgical ligation in a patient with postpartum hemorrhage. Fertil Steril. 2002;78(2):412-413. doi: 1016/S0015-0282(02)03229-6

7. Godfrey CD, Zbella EA. Uterine necrosis after uterine artery embolization for leiomyoma. Obstet Gynecol. 2001;98(5):950-952. doi: 10.1016/S0029-78 44(01)01483-1
8. Ravina JH, Bouret JM, Ciraru-Vigneron N, Repiquet D, Herbreteau D, Aymard A, et al. Recourse to particular arterial embolization in the treatment of some uterine leiomyoma. Bull Acad Natl Med. 1997;181 (2):233-243.

9. Belghiti J, Tassin M, Raiffort C, Zappa M, Poujade O, Bout $\mathrm{H}$, et al. Uterine necrosis after arterial embolization for postpartum hemorhage. Gynecol Obstet Fertil. 2012;42(2):126-128. doi: 10.1016/j.gyobfe.2011.07.045

10. Coulange L, Butori N, Loffroy R, Filipuzzi L, Cercueil JP, Douvier S, et al. Uterine necrosis following selective embolization for postpartum hemorrhage using absorbable material. Acta Obstet Gynecol Scand. 2009;88(2):238-240.

11. Ebové $C$, Barjot $P$, Huet $H$, Jeanne-Pasquier $C$, Herlicoviez M. Uterine and ovarian necrosis following embolisation of the uterine arteries for postpartum haemorrhagia. J Gynecol Obstet Biol Reprod. 2007;36(3):298-301. doi: 10.1016/j.jgyn.2006.12.024

12. Goodwin SC, McLucas B, Lee M, Chen G, Perrella $R$, Vedantham $S$, et al. Uterine artery embolization for the treatment of uterine leiomyomata midterm results. J Vasc Interv Radiol. 1999;10(9):1159-1165. doi: 10.1016/S1051-0443(99)70213-7

13. Payne JF, Haney AF. Serious complications of uterine artery embolization for conservative treatment of fibroids. Fertil Steril. 2003;79(1):128-131. doi: 10.1016/S0015-0282(02)04398-4

14. Pelage JP, Le Dref $O$, Soyer $P$, Kardache $M$, Dahan $\mathrm{H}$, Abitbol $M$, et al. Fibroid-related menorrhagia: treatment with superselective embolization of the uterine arteries and midterm follow-up. Radiology. 2000;215(2):428-431. doi: 10.1148/radiology.215.2.r00mal 1428

15. Poujade O, Daher A, Ballout El Maoula A, Aflak N, Bougeois $B$, Vilgrain $V$, et al. Uterine necrosis following pelvic arterial embolisation for postpartum hemorrhage: case report. J Gynecol Obstet Biol Reprod. 2012;41 (6):584-586. doi: 10.1016/j.jgyn.2012.04.011. 